\title{
Synthesis and Characterization of ZnS: Mn Nanopartilces
}

\author{
Bhaskarjyoti Bodo, Divya Prakash, and P. K. Kalita
}

\begin{abstract}
In this work $\mathrm{Mn}^{2+}$-doped $\mathrm{ZnS}$ nanoparticles were prepared by chemical co-precipitation method at room temperature. The structural and optical properties of the ZnS:Mn nanoparticles were determined by XRD, SEM, UVVisible and FL analyses. XRD analysis showed the sample prepared were in cubic phase with particle size in the ranges $12 \mathrm{~nm}-25 \mathrm{~nm}$. The SEM analysis reveals the growth of nanoparticles agglomerated in different shapes and orientations. In UV_Visible study the band gap energy corresponding to the absorption edge estimated are found to be 4.4 4.3eV which shows the large blue shifting from the bulk band gap 3.6eV of $\mathrm{ZnS}$. The FL peak analysis reveals the strongest absorption at around $329 \mathrm{~nm}$ which is fairly blue shifted from the absorption edge of the bulk (345nm). Thus Mn incorporated into $\mathrm{ZnS}$ nanoparticles results in changing its morphological, structural and optical properties.
\end{abstract}

Index Terms—ZnS: Mn, nanoparticles, SEM.

\section{INTRODUCTION}

Zinc Sulfide (ZnS), a typical II-VI compound semiconductor is a promising opto-electronic device material because of its wide direct band gap $(3.72-3.77 \mathrm{eV})$. Doping on $\mathrm{ZnS}$ with transitional metal ions like $\mathrm{Mn}^{2+}$ and $\mathrm{Cu}^{2+}$ is an important aspect to yield different nanostructures [1]-[9]. Noble luminescence characteristic such as stable light emission with different colors were observed from doped $\mathrm{ZnS}$ nanocrytals at room temperature [1]-[4]. It has been reported that the Mn doped $\mathrm{ZnS}$ has been one of the best efficient electroluminescent (EL) phosphor material in use and its synthesis and properties have widely been investigated [1]-[3], [6]-[9]. In this work we report on a successful synthesis of $\mathrm{Mn}$ doped $\mathrm{ZnS}$ with enhanced luminescence characteristics.

\section{MATERIALS AND METHODS}

\section{A. Synthesis}

A simple chemical co-precipitation method was employed to synthesis $\mathrm{Mn}$ doped $\mathrm{ZnS}$ nanopartilces in colloidal solution [5]. The synthesis was carried out in a matrix solution and thiourea in which $\mathrm{MnCl}_{2}$ solution was added as doping agent. Zinc Sulphate solution of $0.5 \mathrm{M}$ (molarity) was used to get matrix solution and equal volume of thiourea solution of same molarity was prepared. Equal volume of

Manuscript received March 9, 2011; revised April 20, 2012.

B. Bodo is with Department of Physics, Diphu Govt. College, Diphu782462, India (email: jyotibodo@yahoo.co.in).

D. Prakash is with Dept. of Chemistry and Biochemistry, Auburn University, Auburn, Al-36849-5312, USA.

P. K. Kalita is with Nanoscience Research Laboratory, Dept. of Physics, Guwahti College, Guwahti-781022, India. the matrix solution and thiourea were mixed together to form $\mathrm{ZnS}$ and simultaneously $\mathrm{MnCl}_{2}$ Solution of 0.005 morality were added to it as doping agent to get the $\mathrm{Mn}$ doped $\mathrm{ZnS}$ colloidal solution. . The mixture of two salts was the mixed with 3\% solution of poly-Vinyl Alcohol (PVA) and stirred. Finally ammonia solution was added slowly to metal salt solution to form the metal complex and $\mathrm{P}^{\mathrm{H}}$ was adjusted between 10 and 12 .

\section{B. Reaction Mechanism}

The zinc sulphate dissociate into zinc ions in aqueous solution and thiourea dissociate into $\mathrm{S}^{2-}$ ions. Similarly, manganese chloride dissociates into their respective cations and anions. Particles of $\mathrm{ZnS}$ nucleate due to the reaction between $\mathrm{Zn}^{2+}$ and $\mathrm{S}^{2-}$ which subsequently grow by consuming more ions from the solution. Upon nucleation the surface energy of the particle is very high and consequently the surface is passivated by adsorption of anions in the solution $\left(\mathrm{Cl}^{1-}\right.$ and $\left.\mathrm{S}^{2-}\right)$. The accumulation of anions in turn attracts cations $\left(\mathrm{Zn}^{2}\right.$ and $\left.\mathrm{Mn}^{2+}\right)$ on the surface of the particle. $\mathrm{Zn}^{2+}$ and $\mathrm{Mn}^{2+}$ react with $\mathrm{S}^{2-}$ and get incorporated into the crystal lattice of the nucleus.

\section{CHARACTERIZATION}

The structural properties of the $\mathrm{Mn}$ doped $\mathrm{ZnS}$ was investigated using X-ray powder diffractometer (Model: Seifert XRD $3003 \mathrm{~T} / \mathrm{T})$ with $\mathrm{CuK}_{\alpha}$ radiation $(\lambda=0.15406 \mathrm{~nm})$ scanning $2 \theta$ in the range $20^{\circ}-80^{\circ}$. Morphological studies of the as-prepared samples were carried out with Scanning Electron Microscope (SEM) [Model: LEO 1430VP] operated with an acceleration potential of $15 \mathrm{kV}$ to $20 \mathrm{kV}$. The UV-Vis absorption of the samples was recorded using an automated spectrometer (Model: HITACI 113210) in the wavelength range $200 \mathrm{~nm}-800 \mathrm{~nm}$. FL emission spectra were measured with excitation wavelength $325 \mathrm{~nm}$ using AMINC BOWMAN series-2 luminescence spectrometer.

\section{RESULTS AND DISCUSSION}

\section{A. XRD Study}

The Fig.1 represents the XRD of as-prepared Mn doped $\mathrm{ZnS}$ nanoparticles. The XRD measurement reveals that the nanocrytaline of $\mathrm{ZnS}$ has Zinc Blende structure having plane $\{111\},\{200\},\{220]$ and $\{222\}$. The cubic phase of the crystals was identified from the agreement of peak position with standard JCPDS data. It is observed that cubic phase is quite dominant with phases $\{111\},\{200\},\{220\}$ and $\{222\}$. However no peaks from manganese impurities were detected. It may indicate that the $\mathrm{Mn}^{2+}$ ions are dispersed into the $\mathrm{ZnS}$ matrix [3]. The particle sizes and particle size distributions as determined from XRD by using Debye 
Scherrer were in the range $12 \mathrm{~nm}-25 \mathrm{~nm}[10]$. The lattice constant of as-prepared $\mathrm{ZnS}$ nanoparticles are found to be within 5.38-5.41 A which is deviated from Bulk value 5.41A.

The diffraction peaks are considerably broadened that is attributed to the small crystallite sizes [5]. Small crystallites have relatively few lattice planes that contribute to the broadening of the diffraction lines. Broadening the peak may also occur due to the micro-straining of the crystal structure arising from defects like dislocation and twinning etc. These defects are considered to be associated with the chemically synthesized nanocrystals because they grow spontaneously during chemical reaction. In some occasions it could arise due to insufficient energy that is needed for an atom to move a proper site in forming the crystallite.

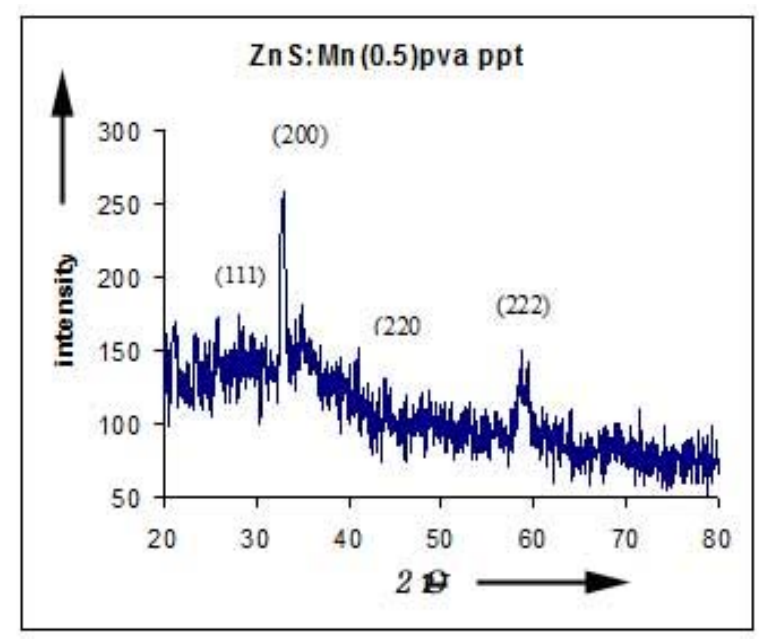

Fig. 1. XRD of ZnS: Mn.

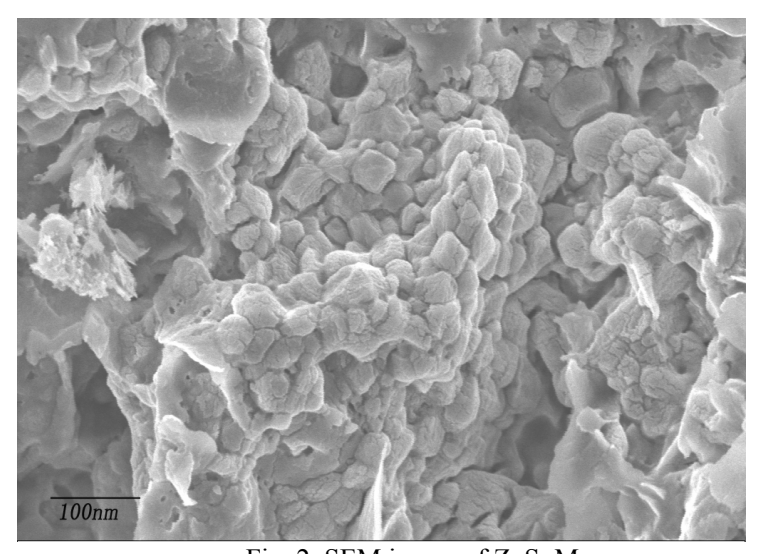

Fig. 2. SEM image of $\mathrm{ZnS}: \mathrm{Mn}$.

\section{B. SEM Study}

A first sight of the produced structures was obtained with the help of SEM which allowed the synthesis of $\mathrm{ZnS}: \mathrm{Mn}$ nanopartilces with different sizes. The Fig. 2 shows the SEM image of as-prepared $\mathrm{Mn}$ doped $\mathrm{ZnS}$ deposited on the thin film and it is observed that the particles size varied from $10 \mathrm{~nm}$ to $35 \mathrm{~nm}$ or more. This growth of nanoparticles agglomerated in different shape and orientation may be attributed due to the uncontrolled nucleation growth during the deposition of nanoparticles on the silica glass substrates.

\section{UV-Visible Study}

The UV-Visible absorption spectra of three Mn doped
$\mathrm{ZnS}$ with (0.5M molarity in PVA) are shown in the Fig. 3. It is observed that absorption edge of the samples are between the wavelength range $280 \sim 285 \mathrm{~nm}$. However the spectra show a clear additional spectrum. The band gap energy corresponding to the absorption edge as estimated are found to be $4.4 \sim 4.3 \mathrm{eV}$ which showed the large shifting from the bulk band-gap $3.6 \mathrm{eV}$ of $\mathrm{ZnS}$. The absorption spectra also shows a clear additional absorption at 345 388nm. Generally the additional absorption near the band gap is considered as exiton energy. Here this absorption is shifted to longer wavelength side compared to the first absorption edge. Therefore this absorption may be attributed to some defects preferably surface.

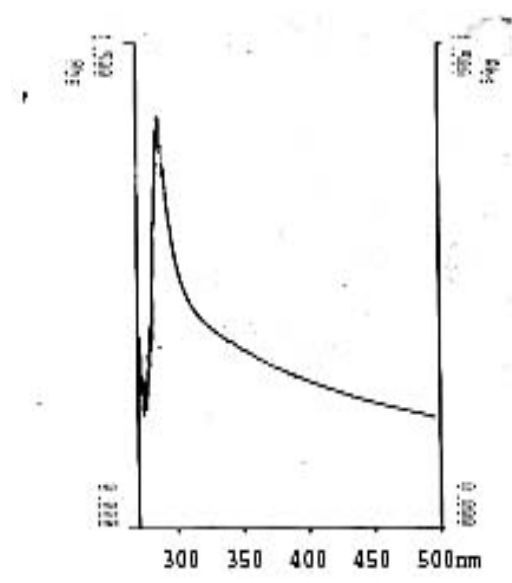

Fig. 3. UV-Vis spectra of $\mathrm{ZnS}$ : Mn.

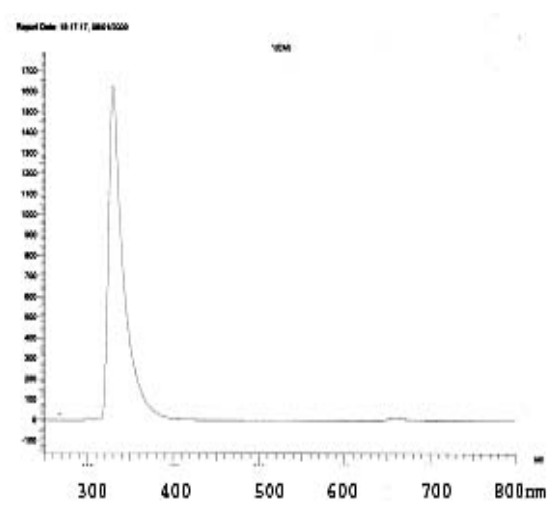

Fig. 4. FL spectra of $\mathrm{ZnS}: \mathrm{Mn}$.

\section{F L Study}

Room temperature fluorescence spectra of the $\mathrm{ZnS}: \mathrm{Mn}$ nanoparticles measured with a $335 \mathrm{~nm}$ excitation are shown in the Fig. 4. The fluorescence spectra recorded for the $\mathrm{Mn}^{2+}$ doped $\mathrm{ZnS}$ showed two absorption edges, one at effective band gap energy of $326 \mathrm{~nm} \sim 329 \mathrm{~nm}$ with direct band gap $3.7 \mathrm{eV} \sim 3.9 \mathrm{eV}$ and other at effective band gap energy of $655 \mathrm{~nm} \sim 660 \mathrm{~nm}$ with direct band gap energy of $1.8 \mathrm{eV} \sim 2 \mathrm{eV}$ [2].The first absorption edge is attributed for the $\mathrm{ZnS}$ host while the latter one is due to the $\mathrm{Mn}^{2+}$ On doping zinc sulfide with manganese, the $\mathrm{Mn}^{2+}$ ions substitute the $\mathrm{Zn}^{2+}$ ions in the $\mathrm{ZnS}$ crystal acting as trap sites, where the electron and holes can be trapped. An electron can undergo photo-excitation process in the host $\mathrm{ZnS}$ lattice of nanoparticles and subsequently decay via a non-radiative transition. The emission could be attributed to the radiative 
decay between these localized states of manganese inside the $\mathrm{ZnS}$ band gap. For doped $\mathrm{ZnS}$ nanoparticles an additional emission spectra due to $\mathrm{Mn}^{2+}$ at energy band bag of $\sim 658 \mathrm{~nm}$ is observed.

\section{CONCLUSION}

$\mathrm{Mn}^{2+}$-doped $\mathrm{ZnS}$ nanoparticles in the colloidal solution form were successfully prepared and their respective size was in the range of $12 \mathrm{~nm}-25 \mathrm{~nm}$. The UV-Visible and F L studies reveal the large blue shifting from the bulk band-gap, (3.6eV) of $\mathrm{ZnS}$ attributing enhanced novel properties. Hence it is observed that $\mathrm{Mn}$ incorporated into $\mathrm{ZnS}$ nanoparticles results in changing its morphological, structural and optical properties.

\section{ACKNOWLEDGEMENTS}

Authors sincerely thank CIF and Dept of Physics, IIT Guwahati-39, Dept of Chemistry, Guwahti University, Guwahti-781013 and SAIF, NEHU, Shillong-793022 for providing the facilities for characterizations.

\section{REFERENCES}

[1] W. Q. Peng, S. C. Qu, G. W. Cong, and Z. G. Wang, "Concentration effect of $\mathrm{Mn}^{2+}$ on the photoluminescence of ZnS: Mn nanocrystals," J. Crystal Growth, vol. 279, pp.454-460, 2005.

[2] P. Yang, M. Lu, D. Xu, D. Yuan, C. Song, S. Liu, and X. Cheng, "Luminescence characteristics of $\mathrm{ZnS}$ nanoparticles co-doped with $\mathrm{Ni}^{2+}$ and $\mathrm{Mn}^{2+}$, , Optical materials, vol. 24, pp. 497- 502, 2003.

[3] A. N. Krasnov, J. P. Bender, and W. Y. Kim, "Increase luminance of $\mathrm{ZnS} / \mathrm{Mn}$ thin-film electroluminescent displays due to Ag Co-doping," Thin Solid Films, vol. 467, pp. 247-252, 2004.

[4] H. Eilers, "Synthesis and Characterization of $\mathrm{CO}_{2}$-laser-evaporated ZnS:Mn thin films," Materials Letters, vol. 62, pp.967-969, 2008

[5] B. Bodo and P. K. Kalita, Chemical Synthesis of ZnS: Cu Nanosheets, AIP. Conf. Proc., vol. 1276, pp.31-35, 2010.

[6] X. HAN, J. LIN, Z. Li, X. QI, M. LI, "Photoluminescent properties of $\mathrm{Ca}_{2} \mathrm{RE}_{2}\left(\mathrm{SiO}_{4}\right)_{6}$ : A Phosphor films prepared by sol gel process," Journal of Rare Earth, vol. 26, no. 3, pp. 443-445, 2008.

[7] N. Karar, S. Raj, and F. Singh, "Properties of nanocrystalline ZnS: Mn," Journal of Crystal Growth, vol. 268, pp. 585-589, 2004.

[8] M. Sima, I. Enculescu, A. ionea, T. Visan, and C. Trautmann, "Manganese and Copper doped CdS Nanowire arrays preparation," Chalcogenide Letters, vol. 1, no. 10, pp.119- 124, 2004.

[9] G. Murugadoss, B. Rajamannan, and U. Madhusudhanan, "Synthesis and characteriszation of water soluble $\mathrm{ZnS}: \mathrm{Mn}^{2+}$ nanoparticles," Chalcogenide Letters, vol. 6, no. 5, pp. 197-201, 2009.

[10] H. P. Klug and E. A. Leory, X-Ray Diffraction Procedures, New York: Wiley, pp.656, 1974. 